\title{
Oral Suspension Final Dosage Form
}

National Cancer Institute

\section{Source}

National Cancer Institute. Oral Suspension Final Dosage Form. NCI Thesaurus. Code C68993.

A suspension composed of a suspension that has been prepared immediately prior to dispensing or oral administration. 